\title{
QUÍMICA ESTELAR E ESTRELAS APOCALÍPTICAS: ESTUDO COMPARATIVO
}

\author{
Nikele Milani ${ }^{1}$, Gabriele Marques Stunges ${ }^{1}$, Éderson da Silva Stelato ${ }^{1}$, Maria Salete Vaceli Quintilio ${ }^{2}$ \\ ${ }^{1}$ Discente do Curso de Química e ${ }^{2}$ Docente do Curso de Física da Universidade do Oeste Paulista (UNOESTE), Presidente Prudente, \\ SP
}

\section{RESUMO}

Todos os átomos existentes no Universo, exceto o Hidrogênio $(\mathrm{H})$ e o Hélio $(\mathrm{He})$, advêm dos processos que ocorrem nas estrelas e de sua evolução. As estrelas transmutam $\circ \mathrm{H} \mathrm{e} \circ \mathrm{He}$ em outros elementos mais pesados através da fusão nuclear e de seu processo evolutivo final, abastecendo e enriquecendo o meio interestelar do qual se originam os sistemas planetários. Entretanto, o mesmo ciclo evolutivo que pode dar origem a um planeta habitável também pode causar a sua destruição, juntamente com as possíveis formas de vida presentes, como por exemplo, em explosões de supernovas, final evolutivo de estrelas massivas. Uma estrela em particular, conhecida como Wolf-Rayet 104 (WR 104), situada a apenas 8000 anos-luz de distancia, encontra-se perto o suficiente da Terra para gerar dúvidas e controvérsias. Além disso, nosso próprio Sol, quando no final de seu ciclo evolutivo, pode trazer consequências funestas para o planeta Terra.

Palavras-chave: nucleossíntese; estrelas; supernova;

\section{STELLAR CHEMISTRY AND APOCALYPTIC STARS: A COMPARATIVE STUDY}

\section{ABSTRACT}

All atoms existing in the Universe, except Hydrogen $(\mathrm{H})$ and helium $(\mathrm{He})$, arise from processes occurring in stars and their evolution. The stars transmute the $\mathrm{H}$ and $\mathrm{He}$ in other heavier elements through nuclear fusion and its process rolling, filling and enriching the interstellar medium from which they originate planetary systems. However, the same evolutionary cycle that can lead to a habitable planet can also cause its destruction, along with possible life forms present, e.g., in supernova explosions, final evolution of massive stars. One particular star, known as Wolf-Rayet 104 (WR 104), situated just 8000 light-years away, is close enough to the Earth to generate questions and controversies. Moreover, our own sun, when at the end of their life cycle, can bring dire consequences for the planet Earth.

Keywords: nucleosynthesis, stars, supernova. 


\section{INTRODUÇÃO}

O universo caracteriza-se por ser constituído de matéria e energia, apresentando uma variedade de corpos, desde partículas subatômicas a galáxias exuberantes, originários do Bing Bang. Os componentes estruturais do universo são as estrelas, corpos que apresentam uma grande quantidade de massa, sendo maiores que os planetas e capazes de gerar energia caracterizada pelas ondas eletromagnéticas como a luz e as ondas de rádio, por exemplo (GREGÓRIO-HETEM; JATENCO-PEREIRA, 2012).

De acordo com Clayton (1968) e Kaufmann III (1998), o processo químico que ocorre no interior das estrelas, que é responsável pela produção de energia e formação de novos elementos químicos, é a fusão nuclear, que constitui no agrupamento de átomos mais simples, formando átomos maiores e mais estáveis, havendo a liberação de muita energia e o surgimento de um novo elemento químico. No Sol, estrela mais próxima da Terra, assim como em muitas outras, 0 processo ocorre constantemente havendo a fusão de átomos de hidrogênio, formando hélio (GREGÓRIO-HETEM; JATENCO-PEREIRA, 2010)

Assim, o que mantém a estabilidade de uma estrela é o equilíbrio entre duas forças concorrentes: 0 colapso gravitacional, proporcionado pela atração que exercem as massas, e a pressão de radiação, devido à energia produzida pela fusão nuclear. Há estrelas anãs, como o Sol, que é uma anã amarela, e estrelas gigantes e supergigantes, que podem apresentar uma massa compreendida entre 0,08 a 100 massas solares ou até mesmo acima de 100 massas solares (OLIVEIRA FILHO; SARAIVA, 2007). As estrelas anãs se caracterizam por apresentar uma vida longa, de aproximadamente 10 bilhões de anos, pois queimam lentamente seu combustível atômico, enquanto as estrelas gigantes e supergigantes têm um tempo de vida curto, em torno de 1 milhão de anos (KAUFMANN III, 1998).

As estrelas anãs produzem elementos químicos leves e quando estão no final de sua vida, aumentam de volume, formando uma gigante vermelha, e posteriomente, acabam ejetando suas camadas mais externas formando as nebulosas planetárias, cujo produto final são os remanescentes nucleares, formando uma anã branca. Já as estrelas gigantes e supergigantes, acabam produzindo elementos químicos mais pesados, consequentemente, no final de suas vidas, os núcleos estelares entram em colapso, e a força da gravidade acaba vencendo a energia do processo de fusão, a estrela perde seu equilibrio, e sofre uma grande explosão denominada de supernova. O resultante da supernova é uma estrela de neutrons ou um buraco negro, os quais podem emitir jatos de radiação gama de longa duração (KAUFMANN III, 1998). O estudo da evolução química de uma estrela, de acordo com Clayton (1968), responde a muitas dúvidas sobre a origem dos átomos e a formação do planeta Terra, o único local do Universo onde temos a certeza de haver seres vivos.

Além disso, é importante a compreensão humana sobre a evolução estelar, desde sua formação até sua morte, pois o final cataclísmico de alguns tipos estelares, além de enriquecer o Universo com átomos pesados, podem também ser os causadores de destruição em massa de planetas e outras estrelas de suas vizinhanças.

Quando uma estrela muito massiva termina seu combustível estelar, seu ciclo evolutivo tem um final violento, numa grande explosão denominada SuperNova. Em tais finais violentos, a emissão de intensa radiação, principalmente na forma de raios gama, traz a 
liberação de uma energia extraordinária, em intervalos de tempo da ordem de apenas alguns segundos. Segundo um estudo feito por Peñate et al. (2010), uma explosão de raios gama nas vizinhanças da Terra, poderia ser extremamente prejudicial para o plâncton do oceano em profundidades que atingem até 75 metros, levando à sua destruição. Como tais microorganismos são responsáveis por $40 \%$ da fotossíntese produzida pelos oceanos, sua destruição poderia produzir um sério impacto sobre os níveis de dióxido de carbono na Terra.

Os objetivos deste trabalho foram: compreender o processo de fusão nuclear no interior das estrelas; analisar a evolução química das estrelas e a formação dos diversos elementos químicos; comparar os estágios evolutivos das possíveis estrelas apocalípticas (WR 104) e uma estrela anã bem próxima da Terra (Sol), e entender como sua morte poderia comprometer a vida e a integridade do planeta.

\section{MATERIAIS E MÉTODOS}

A metodologia envolve pesquisa bibliográfica na literatura e nos meios eletrônicos, como a internet.

A amostra constituiu-se de duas estrelas: a WR 104 e o próprio Sol. Os processos que podem ocorrer no interior de estrelas dessa classe foram analisados e comparados quantitativa e qualitativamente. Também foram compilados e analisados os dados referentes ao vento estelar e emissão de radiação e partículas e sua possível influência na zona de habitabilidade terrestre.

\section{RESULTADOS}

Para o desenvolvimento do presente estudo comparativo da evolução das estrelas Sol e WR104, é necessário a compreensão do processo de fusão nuclear, sendo este descrito a seguir.

\subsection{Nucleossíntese estelar}

Os elementos químicos que compõem a Tabela Periódica são produzidos através da nucleossíntese em estrelas, explosões de Supernovas ou, ainda, advém do próprio Big Bang.

$\mathrm{Na}$ Figura 1, apresentamos a tabela periódica com os elementos químicos que são sintetizados pelo Big Bang, supernovas, estrelas e raios cósmicos.

\begin{tabular}{|c|c|c|c|c|c|c|c|c|c|c|c|c|c|c|c|c|c|}
\hline $\mathrm{H}$ & \multirow{3}{*}{$\mathrm{Be}$} & & \multirow{3}{*}{\multicolumn{4}{|c|}{$\begin{array}{l}\square \text { Big Bang } \\
\square \text { Supernovae } \\
\square \text { Large Stars }\end{array}$}} & \multirow{3}{*}{\multicolumn{5}{|c|}{$\begin{array}{l}\square \text { Small Stars } \\
\square \text { Cosmic Rays }\end{array}$}} & \multicolumn{6}{|c|}{$\mathrm{He}$} \\
\hline \multirow{2}{*}{\begin{tabular}{|c|}
$\mathrm{Li}$ \\
$\mathrm{Na}$ \\
\end{tabular}} & & & & & & & & & & & & B & C & $\mathrm{N}$ & 0 & $\mathrm{~F}$ & $\mathrm{Ne}$ \\
\hline & & & & & & & & & & & & $\mathrm{Al}$ & Si & $P$ & $S$ & $\mathrm{Cl}$ & $\mathrm{Ar}$ \\
\hline $\mathrm{K}$ & $\mathrm{Ca}$ & $\mathrm{Sc}$ & $\mathrm{Ti}$ & $\mathrm{V}$ & $\mathrm{Cr}$ & $\mathrm{Mn}$ & $\mathrm{Fe}$ & $\mathrm{Co}$ & $\mathrm{Ni}$ & $\mathrm{Cu}$ & $\mathrm{Zn}$ & $\mathrm{Ga}$ & $\mathrm{Ge}$ & As & $\mathrm{Se}$ & $\mathrm{Br}$ & $\mathrm{Kr}$ \\
\hline$\overline{R b}$ & $\mathrm{Sr}$ & $Y$ & $\mathrm{Zr}$ & $\mathrm{Nb}$ & Mo & Tc & $R_{L}$ & $\mathrm{RH}$ & $\mathrm{Po}$ & $\mathrm{Ag}$ & $\mathrm{Cd}$ & In & Sn & $\mathrm{Sb}$ & $\mathrm{Te}$ & 1 & $\mathrm{Xe}$ \\
\hline Cs & $\mathrm{Ba}$ & & $\mathrm{Hf}$ & $\mathrm{Ta}$ & w & $\operatorname{Re}$ & Os & Ir & $P$ & $\mathrm{Au}$ & $\mathrm{Hg}$ & $\mathrm{TI}$ & $\mathrm{Pb}$ & $\mathrm{Bi}$ & Po & $\mathrm{At}$ & $\mathrm{Rn}$ \\
\hline & & & & & & & & & & & & & & & & & \\
\hline & & & $\mathrm{La}$ & $\mathrm{Ce}$ & $\mathrm{Pr}$ & $\mathrm{Nd}$ & $\mathrm{Pm}$ & $\mathrm{Sm}$ & $\mathrm{Eu}$ & $\mathrm{Gd}$ & $\mathrm{Tb}$ & Dy & $\mathrm{Ho}$ & $\mathrm{Er}$ & $\mathrm{Tm}$ & & Lu \\
\hline & & & $A C$ & Th & $\mathrm{Pa}$ & $U$ & $\mathrm{~Np}$ & $\mathrm{Pu}$ & Am & $\mathrm{Cm}$ & $\mathrm{Bk}$ & $\mathrm{Cf}$ & Es & $\mathrm{Fm}$ & & No & $\mathrm{Lr}$ \\
\hline
\end{tabular}

Figura 1. Nucleossíntese dos elementos.

Fonte: http://www.universetoday.com/70646/astronomywithout-a-telescope-alchemy-by-supernova/

Castro (2010) relata a origem de cada elemento químico da tabela periódica apresentada na Figura 1: o hidrogênio $(H)$ e hélio (He) são elementos primordiais, ou seja, foram sintetizados durante o Big Bang. Observa-se que todas as estrelas são formadas basicamente por $\mathrm{H}$ e inicialmente produzem $\mathrm{He}$. As estrelas com massas da ordem da massa solar, sintetizam os seguintes elementos: carbono $(\mathrm{C})$, nitrogênio $(\mathrm{N})$, oxigênio $(\mathrm{O})$, neônio ( $\mathrm{Ne}$ ) e enxofre (S) até chegar no Ferro (Fe). Estrelas maiores podem continuar o processo de nucleossíntese com elementos mais pesados como o Cobre $(\mathrm{Cu})$, Zinco $(\mathrm{Zi})$ até Itérbio (Yb). Já os elementos o Lítio (Li), Berílio (Be) e o Boro (B) são provenientes de raios cósmicos; as supernovas, sendo o final de 
estrelas muito massivas, são os únicos meios de produzir todos os elementos da tabela periódica.

Conforme os átomos são formados e dispersos no espaço por meio de ventos estelares e explosões de supernovas, o meiointerestelar vai sendo enriquecido e, posteriormente, produzem as nuvens interestelares das quais se formam estrelas e planetas (SANTO, 2009).

Assim, a primeira geração de estrelas, nascidas após o Big Bang, eram formadas exclusivamente por $\mathrm{H}$ e um pouco de He. Conforme as gerações estelares evoluiam e morriam, o enriquecimento o meio interestelar permitiu a dispersão dos elementso mais pesados obtidos da nucleossíntese dessas estrelas (FARIAS, 2008).

A fim de estabelecer um caminho evolutivo das estrelas, Santo (2009, p.23) relata que o diagrama de Hertzprung-Russell, mostrado na Figura 2, foi:

[..] criado em 1910 por Ejnar hertzprung e Henry Norris Russel, mostra a relação entre luminosidade, cor, temperatura efetiva e magnitude absoluta da estrela. O diagrama HR é usado para definir os diferentes tipos de estrelas e para verificar precisões teóricas sobre a evolução estelar utilizando observações de estrelas e modelos computacionais.

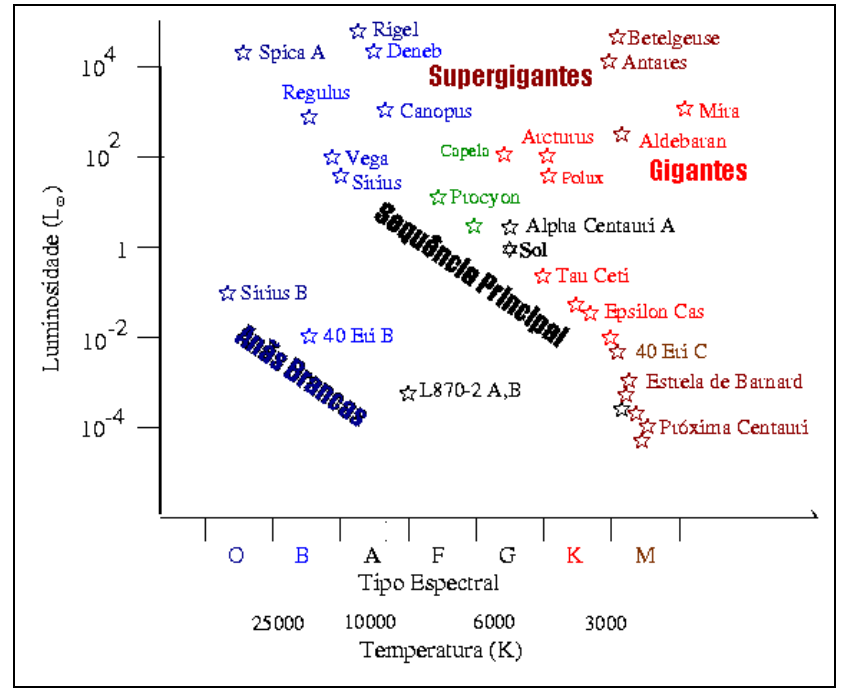

Figura 2. Diagrama Hertzprung-Russell. Fonte: http//astro.if.ufrgs/estrelas/node10.htm.
De acordo com Oliveira Filho e Saraiva (2004), a Figura 2 mostra que a maior parte das estrelas está concentrada numa faixa diagonal denominada sequência principal, que vem da parte superior esquerda, onde se encontram as estrelas mais quentes e muito luminosas e vão até a parte inferior direita, onde estão localizadas as estrelas maisfrias e menos luminosas.

O fator principal que determina a localização de uma estrela no diagrama HR é sua massa, porque quanto maior a massa, mais quente e luminosa será a estrela.

As estrelas começam sua vida na sequência principal fazendo a fusão de $\mathrm{H}$ em $\mathrm{He}$, independente da sua massa, a qual determinará a permanência nessa fase, pois as estrelas de maior massa queimam mais rapidamente 0 hidrogênio (OLIVEIRA FILHO; SARAIVA, 2004).

As estrelas se aproximam do estágio final quando, ao terminar a fusão do hidrogênio nuclear, começam a queimar o hidrogênio das camadas exteriores e deixam a sequência principal (REES, 2008).

A Figura 3 apresenta de forma ilustrativa a seguência da evolução das estrelas do começo ao fim e isso depende de sua massa solar.

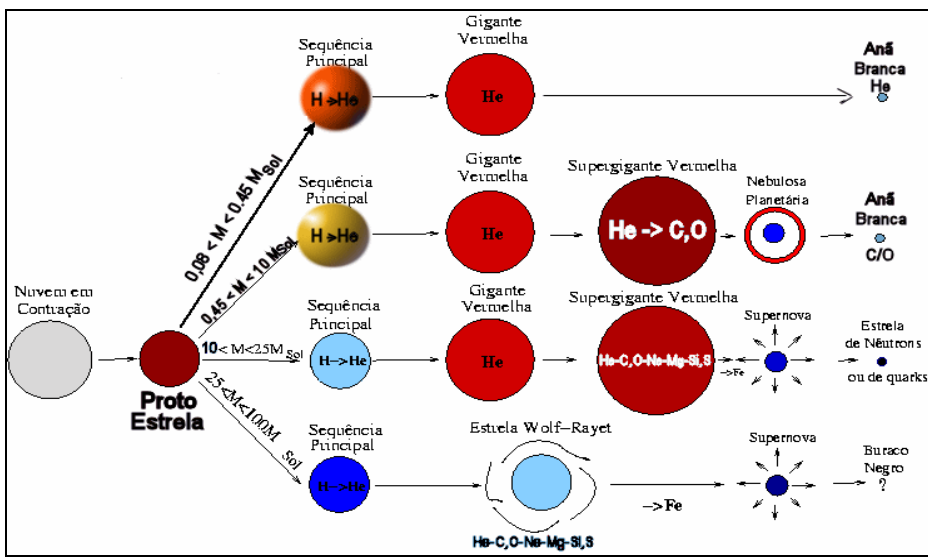

Figura 3. Evolução estelar.

Fonte: http://astro.if.ufrgs.br/estrelas/explorestrelas.htm.

O processo de fusão nuclear que ocorre no interior das estrelas possibilita a síntese dos diversos elementos químicos além de gerar a 
energia necessária para a estrela brilhar e deter o colapso gravitacional.

O processo de fusão mais comum, que transforma $\mathrm{H}$ em $\mathrm{He}$, é chamado ciclo prótonpróton ( $p-p)$. Para deflagar esse processo é necessário que a estrela atinja temperaturas da ordem de 8 milhões de Kelvins (OLIVEIRA FILHO; SARAIVA 2007).

A equação 1 representa o ciclo $p-p$, onde átomos de $\mathrm{H}$ são transformados em átomos de He, liberando partículas de alta energia, como neutrinos $\left(\mathbf{v}_{\mathrm{e}}\right)$ e pósitrons $\left(\mathrm{e}^{+}\right)$, e energia na forma de raios gama $(\mathrm{V})(\mathrm{CAIBO}, 2001)$.

$$
4 \mathrm{H} \rightarrow \mathrm{He}^{4}+2+2+\mathrm{y} \quad \text { Equação } 1
$$

Fonseca (2005, p. 25) explica que "a reação de fusão nuclear ocorre quando a energia cinética de dois núcleos leves é suficiente para vencer a barreira colombiana de repulsão entre estes".

Contudo, outro processo de fusão nuclear ocorre nas estrelas mais massivas, denominado Ciclo do Carbono (CAIBO, 2001). A figura 5 mostra as reações nucleares que ocorrem nos interiores de estrelas cujas temperaturas são maiores que a temperatura no nucleo do Sol.

Santos (2011, p.1) explica esse ciclo de carbono da seguinte forma:

Esse ciclo [...] tem inicio com a fusão de um núcleo de hidrogênio e um núcleo de carbono, tendo como produtos um isótopo do nitrogênio e radiação gama. Após a inserção de mais três núcleos de hidrogênio, o ciclo termina, tendo como produtos 0 núcleo de hélio e o núcleo de carbono.

No ciclo de carbono, também chamado ciclo de carbono-nitrogênio-oxigênio ( $\mathrm{C}-\mathrm{N}-\mathrm{O})$, são necessárias temperaturas superiores a $18 \times 10^{6}$ $\mathrm{K}$, que ocorrem em estrelas com massa inicial acima de 1,2 $\mathrm{M}_{\odot}$. Estas estrelas utilizam os elementos carbono e nitrogênio como catalisadores do processo (OLIVEIRA FILHO; SARAIVA 2004).

Segundo Gregório-Hetem e JatencoPereira (2010, p. 139), as equações 2 a 11 ocorrem nas estrelas com massas iniciais entre 0,8 e $10 M_{\odot}$ após consumirem o hidrogênio nuclear, iniciando a fase de gigante vermelha e em seguida a de supergigante vermelha. Nestas estrelas, o núcleo não é quente o suficiente para continuar o processo de fusão transformando o carbono em elementos mais pesados, e a estrela passa para a fase de nebulosa planetária (NP), ejetando suas camadas exteriores.

De acordo com Friaça et al. (2008), a estrela começa a se contrair devido à força gravitacional, pois a pressão térmica não é mais suficiente para deter o colapso gravitacional, até que a temperatura se estabiliza e a produção de energia se reinicia nas camadas exteriores, que ainda tem hidrogênio e hélio para fundir. Tal processo provoca a instabilidade que acaba resultando na expulsão das camadas exteriores da estrela, num evento de NP e a estrela acabará a sua trajetória evolutiva como uma anã branca.

Em estrelas mais massivas, acima de 8 massas solares, as temperaturas são suficientes para obter a fusão do Carbono em elementos mais pesados e a estrela passa para a fase gigante vermelha depois de iniciar a fusão do $\mathrm{He}$. Esse processo acontece sem alterações drásticas e a estrela queima seu combustível em camadas, como se fosse uma cebola (GREGÓRIO-HETEM; JATENCO-PEREIRA, 2010), conforme a Figura 4.

A partir deste momento, Farias (2008) e Oliveira Filho e Saraiva (2004) explicam que quando cessa a fusão nuclear, a estabilidade da estrela é perdida. Ao formar ferro no núcleo, a estrela não produz mais energia e se colapsa, numa explosão denominada Supernova, liberando elementos químicos mais pesados no meio interestelar. A partir desse momento, o que 
sobra é uma estrela de nêutrons ou ainda um buraco negro.

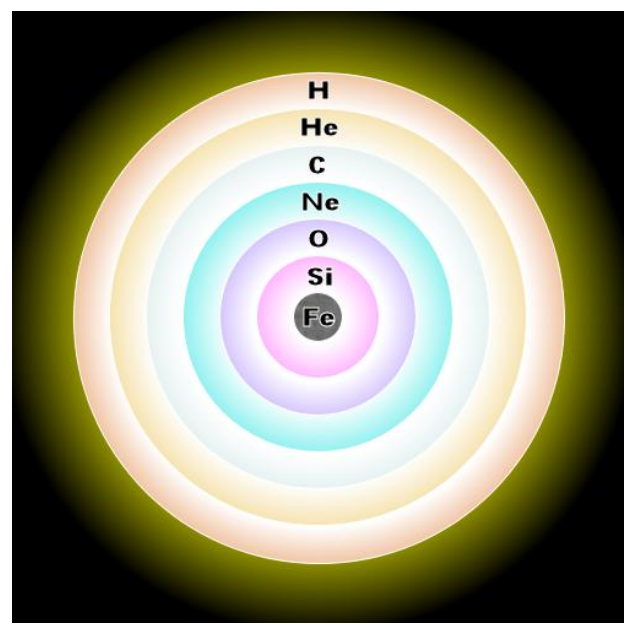

Figura 4. Camadas de uma estrela massiva. Fonte: http://eternosaprendizes.com/2010/08/17/comofunciona-a-alquimia-das-estrelas-a-nucleossintese-doselementos-quimicos-no-universo/

Segundo Clayton (1968) a nucleossíntese de elementos químicos mais pesados que o ferro $\left(\mathrm{Fe}^{56}\right)$ pode ocorrer através de três tipos de captura, tendo-se a captura de nêutrons (processo-s e $-r$ ) e a captura de prótons (processo-p).

A captura de nêutrons inicia-se com as colisões e fusões dos nêutrons, obtendo-se núcleos com muitos nêutrons e maior massa, com igual número atômico, sendo esse núcleo um isótopo. O isótopo formado pode ser estável ou instável. Sendo instável, pode provocar o decaimento radioativo espontâneo, chamado decaimento-beta, pois 0 elétron com 0 antineutrino são emitidos e a conversão de um dos nêutrons do núcleo em um próton, e com essa modificação do número de prótons, gerando-se assim um novo elemento.

Se a captura de nêutrons for pelo processo-s (ou processo lento), Ramos (2007) diz que o núcleo atômico instável formado sofre o processo de decaimento-beta antes da captura de mais nêutrons, gerando um átomo com um próton a mais ou a menos. Esse processo é encontrado nos estágios finais de estrelas como o sol (gigantes vermelhas), pois quando vai se transformando em uma anã branca são produzidos nêutrons (sobretudo do decaimento do carbono e do neônio).

Segundo Castro (2010), o processo-s é capaz de produzir elementos mais pesados a partir do ferro (26 prótons), desde Cobre (Cu) com 29 prótons até o Tálio (TI) com 81 prótons.

No caso de captura de nêutrons pelo processo-r (ou processo rápido), Ramos (2007) relata que, durante o colapso de uma estrela com núcleo de ferro (supernova), são liberados muitos nêutrons e com isso, o núcleo instável formado terá mais tempo para capturar mais nêutrons antes de sofrer o decaimento-beta.

De acordo com Castro (2010), no processo-r são formados elementos que não poderiam ser feitos pelo processo-s, que vão desde o chumbo $(\mathrm{Pb})$ com 82 prótons até o Plutônio $(\mathrm{Pu})$ com 94 prótons.

O outro processo que Ramos (2007) explica é a captura de prótons (processo-p), que ocorre quando os prótons estão quentes e contém energia suficiente para atravessar a barreira colombiana, que se forma devido à repulsão do próton quando se aproxima do núcleo, para conseguir fundir com o núcleo para formar novos elementos mais pesados. Isso acontece nos sistema binário, pois uma das estrelas atrai para si o gás formado de hidrogênio da outra, gerando prótons.

\subsection{Estrelas tipo solar}

A massa do Sol é de aproximadamente de $M_{\odot}=1,9891 \times 10^{30} \mathrm{~kg}$, contida num raio de 6,96 x $10^{6} \mathrm{~m}$ (100 vezes o raio da Terra). Essas dimensões dão ao Sol uma densidade média $40 \%$ maior que a da água. O Sol dista 150 milhões de $\mathrm{Km}$ da Terra e emite radiação em todo o espectro magnético, concentrando sua máxima intensidade 
na região do visível, ultravioleta e infravermelho (SILVA, 2006).

A composição do Sol é, em sua maior parte, hidrogênio, um pouco de Helio e traços de outros elementos. Esses gases estão aquecidos a altas temperatura, formando o plasma solar ionizado. Na superfície do Sol, a temperatura é de $5800 \mathrm{~K}$ e em seu centro pode chegar a $15000 \mathrm{~K}$ (SANTOS, 2011). É no centro do sol que ocorrem as reações termo-nucleares de transformação de hidrogênio em hélio, gerando grandes quantidades de energia na forma de fótons e movimentos térmicos (GREGORIO-HETEN; JATENCO PEREIRA, 2010).

Como se trata de uma estrela pequena, o sol não se tornará uma supernova, mas atingirá a fase de Gigante Vermelha, na qual continuará sendo um imenso reator nuclear que queima hidrogênio para gerar energia, fundindo átomos de hidrogênio transformando-os em hélio e energia (O UNIVERSO 2007). Mas com o tempo o núcleo vai ficando pobre em hidrogênio e mais rico em hélio. Isso porque não existe uma convecção vertical do núcleo para a camada rica em hidrogênio, porém o sol tem um mecanismo que mantém seu equilíbrio hidrostático. Esse mecanismo começa com a contração do núcleo, o que aumenta sua pressão e temperatura dando condições para que a taxa de fusão do hidrogênio acelere, aumentando assim a luminosidade da estrela (CHAVES, 2011). Quando o núcleo do sol se tornar uma massa de hélio, sua temperatura não será suficiente para que ocorra a fusão então ele irá se contrair até chegar aproximadamente ao tamanho da Terra e a temperatura se elevara a 100 milhões de graus, alta o suficiente para fundir núcleos de He-4 em C-12 e O-16. Em uma estrela pequena como o Sol, o início da produção do carbono é também o começo da sua morte. Em uma estrela que está morrendo, o equilíbrio entre a gravidade que puxa para dentro e a pressão que empurra para fora acaba, a gravidade começa a contrair o núcleo e a pressão externa empurra os gases para fora, que se dilatam formando uma imensa bola de gás chamada de gigante vermelha. A cor vermelha é devido ao seu esfriamento, pois ela se expandirá tanto que vai começar a esfriar, porém sua luminosidade será muito grande devido ao imenso tamanho, chegando a engolir a Terra e planetas próximos. Enquanto isso a gravidade comprimirá o núcleo a um milionésimo do seu tamanho original e o sol se tornará uma bola de oxigênio e carbono chamada de anã branca, que é um corpo em que os elétrons são tão comprimidos no núcleo que uma colher de sopa feita desse material pesaria várias toneladas. 0 gás que estava a sua volta se expandirá e se dispersará no universo, formando uma Nebulosa Planetária (O UNIVERSO 2007). A Figura 5 mostra o processo de evolução do sol.

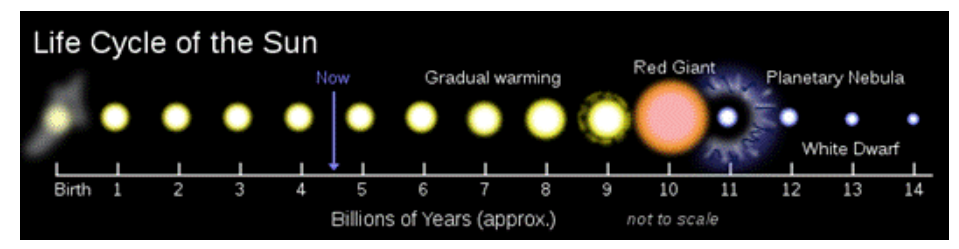

Figura 5. Ilustração da evolução do Sol. Os tamanhos não estão em escala.

Fonte: http://www.observatorio.ufmg.br/Pas104.htm

\subsection{Estrela Wolf-Rayet 104}

A estrela Wolf-Rayet 104 (WR 014) é uma estrela massiva localizada na constelação de sagitário, distante 8.000 anos-luz do planeta Terra. Esta estrela se caracteriza por apresentar um raio 3 vezes maior que o raio solar e tem massa 25 vezes a massa do Sol (TUTHILL, 2009). A estrela foi descoberta em 1998 através do telescópio de infravermelho Keck I, cuja fotografia registrada (Figura 6), foi a seguinte: 


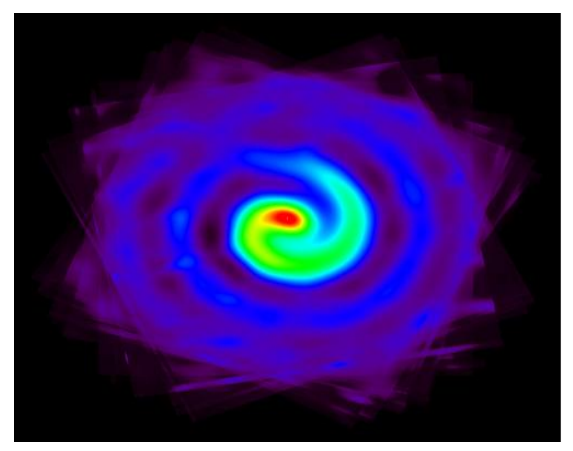

Figura 6. Estrela Wolf-Rayet 104.

Fonte: Tuthill (2009)

A partir da imagem captada, nota-se a presença de uma espiral de plasma estelar ao redor da estrela de 160 unidades astronômicas. Segundo Tuthill (2009), essa espiral de plasma é decorrente da estrela WR 104 estar perdendo bastante massa e pelo fado de WR 104 pertencer a um sistema binário, cuja companheira (estrela OB) também libera uma certa massa de plasma e que ao se colidir com o plasma da WolfRayt forma um vento de plasma em espiral que acompanha o movimento orbital de ambas as estrelas.

De acordo com Plait (2008), devido à estrela WR 104 estar liberando elevada quantidade de vento estelar e por ser massiva, essa estrela irá sofrer uma explosão do tipo supernova, cujo tempo para tal explosão é indeterminado devido à distância da estrela do planeta Terra, pois como há muito poeira de plasma entre a estrela e a Terra, torna-se difícil determinar a real idade da estrela. No entanto, o mais importante é determinar qual será o tipo de supernova que a estrela irá formar: caso seja uma supernova comum, onde o núcleo e o material remanescente da estrela se transformam numa estrela de nêutrons (pulsares ou magnetares), tal explosão não afetará a Terra. A essa distância de 8.000 anos-luz, apenas será detectado um brilho no céu no noturno. Porém, caso a estrela forme uma super nova do tipo explosão de raios gama, onde o núcleo estelar se colapsa em um buraco negro, são emitidos jatos de plasma altamente energéticos, constituídos de radiação eletromagnética e partículas subatômicas excitadas nos polos dos remanescentes, e que se deslocam a uma velocidade próxima da luz. Segundo Tuthill (2008), o planeta Terra pode estar na mira desse possível jato de plasma que a estrela poderá formar, pois a partir da imagem captada da estrela, nota-se que a partir do planeta Terra é visível um dos pólos da estrela, que aparenta ter 12 graus de inclinação a partir do campo de visão frontal, mas como é difícil determinar essa medida com precisão, o grau de inclinação do pólo da estrela pode variar entre 0 a 16 graus.

Caso o planeta Terra seja atingido por esse jato de plasma altamente energético, segundo Plait (2008), o planeta não seria destruído, mas ocorreria um evento de extinção em massa dos seres vivos que compõem o planeta. Pois a radiação eletromagnética proveniente do jato estelar alteraria drasticamente a atmosfera do planeta, sendo que $30 \%$ da camada de ozônio seriam destruídos, permitindo uma grande incidência de raios ultravioleta do sol alterando o DNA de vários seres vivos que sofreriam mutações incompatíveis com a vida, como o caso do câncer em seres humanos, e, além disso, ocorreria a formação do smog (gás escuro), decorrente da degradação do ozônio $\left(\mathrm{O}_{3}\right)$ juntamente com a do nitrogênio molecular $\left(\mathrm{N}_{2}\right)$, que resulta no dióxido de nitrogênio $\left(\mathrm{NO}_{2}\right)$, que apresenta uma coloração marrom, que poderia dificultar a incidência de luz solar que é canalizada pelos vegetais na fotossíntese, e ainda poderia se precipitar com o água presente na atmosfera causando chuva ácida, que causaria corrosão tanto em materiais produzidos naturalmente e artificialmente pelo homem. E, além dos problemas decorrentes da radiação eletromagnética do jato de plasma, as partículas subatômicas altamente excitadas presentes no jato causariam efeitos mais drásticos, por serem 
altamente radioativos, sendo que o local do planeta que fosse atingindo por essas partículas, seria praticamente esterilizado.

Logo, a estrela WR 104 pode ser considerada como uma estrela do tipo gigante que pode se tornar apocalíptica quando seu núcleo colapsar em ferro e assim gerar uma supernova. Embora isso seja possível, não há ainda motivos concretos para os seres vivos terrestres se preocuparem, uma vez que, segundo Plait (2008), muitas incertezas a respeito dessa estrela, tais como, o grau de inclinação de seu polo com Terra, se sua massa é suficiente para colapsar em um buraco negro e sofrer uma explosão de raios gama, e sua real distância do planeta Terra, que pode ser maior ou menor que os 8000 anos-luz estimados (TUTHILL, 2008). Por isso a estrela WR 104 é, por enquanto, apenas um objeto do universo com muitos mistérios a serem descobertos.

\section{DISCUSSÃO}

Independente de sua massa inicial, a estrela a Sequencia Principal, funde $\mathrm{H}$ em He até que $\circ \mathrm{H}$ se esgota e a estrela passa a produzir novos elementos, como $\mathrm{C}, \mathrm{N}$ e O , até obter $\mathrm{Fe}$ em seu núcleo. Após esta fase, estrelas de baixa massa, como o Sol, se tornam Gigantes Vermelhas, perdendo massa gradativa $e$ lentamente para o espaço, até restar um núcleo quente, denominado de anã branca. Estrelas mais massivas, como as WR tem evolução muito mais acelerada e sofrem uma grande explosão denominada Supernova (SN), que promove a formação de elementos ainda mais pesados, e frequentemente libera jatos de radiação gama de seus polos de rotação, que poderia ser prejudicial a qualquer objeto celeste em seu caminho.

Analisando as estrelas estudadas podemos concluir que a estrela que apresenta mais perigo para o planeta Terra é a estrela WR 104, pois, como ela se encontra muito distante da
Terra não sabemos com certeza sua idade ou se ela já morreu, caso isso tenha acontecido não se sabe também quanto tempo levará para que a radiação emanada por ela em sua morte chegue até aqui, pois também não é sabido quando ela morreu, o que nos leva a pensar que a qualquer momento o planeta Terra pode receber uma quantidade muito grande de radiação gama que poderá dizimar a vida aqui.

Quando o nosso Sol morrer sabe-se com certeza que esse acontecimento levará todas as espécies de vida a extinção, pois ao se tornar uma gigante vermelha, ele ficará tão grande que seu raio alcançará a Terra e irá consumi-la com seu calor. Para alívio de todos sabe-se que o Sol tem combustível suficiente para ser consumido por aproximadamente mais uns 5 bilhões de anos, tempo suficiente para que se estudem possibilidades de salvação para a humanidade.

\section{CONCLUSÃO}

O planeta Terra, eventualmente, terá sua integridade comprometida, pois o próprio Sol, que promoveu o seu surgimento e o desenvolvimento da vida, ao entrar em sua fase de gingante vermelha, destruirá toda a zona de habitabilidade do Sistema Solar. Além disso, estrelas hipergigantes, ao se tornarem supernovas, podem causar extinção em massa no planeta, como a WR 104, que poderá bombardear a Terra com intensos jatos de radiação gama, novamente colocando em risco a habitabilidade do planeta.

\section{REFERÊNCIAS}

CAIBO, S. R. Século XX - Astronomia e astronáutica a evolução estelar. 2001. Disponível em: < http://www.cdcc.usp.br/cda/sessaoastronomia/seculoxx/textos/a-evolucaoestelar.htm >. Acesso em: 28 dez. 2011.

CASTRO, R. Como funciona a alquimia das estrelas? A nucleossíntese dos elementos químicos no Universo. 2010. Disponível em: http://eternosaprendizes.com/2010/08/17/comofunciona-a-alquimia-das-estrelas-a- 
nucleossintese-dos-elementos-quimicos-nouniverso/ Acesso em: 28 fev. 2012.

CHAVES, A. Evolução estelar. 2011. Disponível em: <http://www.observatorio.ufmg.br/Pas104.htm > Acesso em 04 set. 2012.

CLAYTON, D. D. Principles of stellar evolution and nucleosynthesis. New York: McGraw-Hill Book Company, 1968.

FARIAS, T. M. B. Estudo das propriedades termoluminescentes e de absorção óptica de oito variedades de quartzo. São Paulo, 2008. 81f. Tese (Doutorado) - Universidade de São Paulo. Instituto de Física. Disponível em: <http://www.teses.usp.br/teses/disponiveis/43/431 34/tde-15042009-165630/pt-br.php>. Acesso em: 13 jan. 2012.

FONSECA, A. M. M. Emissão eletrociclotrônica no tokamak TCABR: um estudo experimental. São Paulo, 2005. 211f. Tese (Doutorado) Universidade de São Paulo. Instituto de Física Departamento de Física Aplicada. Disponível em: <http://www.teses.usp.br/teses/disponiveis/43/431 34/tde-29092005-132047/pt-br.php>. Acesso em: 13 jan. 2012.

FRIAÇA, A. C.S; DAL PINO, E.; SODRÉ Jr., L.; JATENCO-PEREIRA, V. Astronomia: uma visão geral do universo. 2.ed. são Paulo: Editora da Universidade de São Paulo, 2008.

GREGORIO-HETEM, J.; JATENCO-PEREIRA, V. Fundamentos de astronomia. 2010. Disponível em:<

http://www.telescopiosnaescola.pro.br/aga215/ag a215.html >. Acesso 08 set. de 2012.

KAUFMANN III, W. J.; FREEDMAN, R. A. Universe. 4. ed. New York: W. H. Freeman and Company, 1998.

O UNIVERSO: Segredos do Sol, Ep.1. Dirigido por Douglas J. Cohen. Produção: The History Channel. Distribuição: LOG ON Editora Multimídia. 2007.

OLIVEIRA FILHO, K. S.; SARAIVA, M.F.O. Astronomia e Astrofísica. 2. ed. São Paulo: Livraria da Física, 2004.

OLIVEIRA FILHO, K. S.; SARAIVA, M. F. O. Astronomia e Astrofísica. 2007. Disponível em: < http://astro.if.ufrgs.br/index.htm >. Acesso em: 28 fev. 2012.

PEÑATE, L. et al. Short-term effects of gamma ray bursts on oceanic photosynthesis. Astrophysics and Space Science. v.330, n.2, pp.211-217, 2010.
PLAIT, P. WR 104: A nearby gamma-ray burst? In: Discover magazine. New York: Corey S. Powell, 2008. Disponível em:< http://blogs.discovermagazine.com/badastronomy/ 2008/03/03/wr-104-a-nearby-gamma-ray-burst/ >. Acesso em: 17 jul. 2012.

REES, M. O Reino das Galáxias. São Paulo: Duetto Editorial, 2008.

SANTO, M. G. Estudo de reações nucleares de interesse astrofísico utilizando o método de cavalo de troia. São Paulo, 2009. 180f. Tese (Doutorado) - Universidade de São Paulo. Instituto de Física. Disponível em: $<$ http://www.teses.usp.br/teses/disponiveis/43/431 34/tde-07042009-161106/pt-br.php>. Acesso em: 03 mar. 2012.

SANTOS, T. J. Sol: estrutura e evolução. In: UFMG Observatório Astronômico Frei Rosário. $2011 . \quad$ Disponível em: <http://www.observatorio.ufmg.br/pas25.htm> Acesso em: 04 set. de 2012.

SILVA, A. V. R. Nossa estrela: o sol. 1.ed. São Paulo: Livraria da Física, 2006.

TUTHILL, P.; MONNIET, J. D.; LAWRANCE, N.; Danchi, W. C.; OWOCKI, S. P.; GAYLEY, K. J. The Prototype Colliding-Wind Pinwheel WR 104. The Astrophysical Journal. v. 675, n. 1, p. 698710, 2008.

TUTHILL, P. The twisted tale of wolf-rayet 104 first of the pinwheel nebulaebula. In: The University of Sydney. Sydney: Scholl Of Physic, 2009. Disponível em:< http://www.physics.usyd.edu.au/ gekko/wr104.ht ml>. Acesso em: 25 jul. 2012.

TUTHILL, P. WR 104: The prototype pinwheel nebula. In: The University of Sydney. Sydney: Scholl Of Physic, 2009. Disponível em:< http://www.physics.usyd.edu.au/ gekko/pinwheel. html>. Acesso em: 20 jul. 2012. 